\title{
Epidemiology of asthma and associated factors in an urban Pakistani population: adult asthma study-Karachi
}

\author{
Shama Razzaq ${ }^{1}$, Asaad Ahmed Nafees ${ }^{1,5^{*}}$ (D) Unaib Rabbani ${ }^{2}$, Muhammad Irfan ${ }^{3}$, Shahla Naeem ${ }^{1,6}$, \\ Muhammad Arslan Khan ${ }^{1}$, Zafar Fatmi ${ }^{1}$ and Peter Burney ${ }^{4}$
}

\begin{abstract}
Background: This study was conducted in order to determine the prevalence of asthma and associated risk factors in the adult population of Karachi, Pakistan.

Methods: This multi-stage, cross-sectional survey was conducted from May 2014-August 2015; comprising 1629 adults in 75 randomly selected clusters in Karachi, Pakistan. Definitions included: 'self-reported asthma', 'reversibility in $\mathrm{FEV}_{1}$ ' and 'respiratory symptoms and reversibility in $\mathrm{FEV}_{1}$ '.

Results: Prevalence of asthma was 1.8\% (self-reported) (95\% Cl: 1.0-2.6), 11.3\% (reversibility in $\mathrm{FEV}_{1}$ ) (95\% Cl: 9.4-13.3) and 6.6\% (symptoms and reversibility in $\left.\mathrm{FEV}_{1}\right)(95 \% \mathrm{Cl}: 5.1-8.1)$. Asthmatics were more likely to belong to the age group $\geq 38$ years according to 'reversibility in $\mathrm{FEV}_{1}$ ' and 'respiratory symptoms and reversibility in $\mathrm{FEV}_{1}$ ' $(\mathrm{AOR}: 1.9,95 \% \mathrm{Cl}$ : 1.2-3.3) and (AOR: 2.1, 95\% Cl: 1.1-4.2), respectively. Asthmatics were more likely to report history of allergies (AOR: 1.9, 95\% Cl: 1.2-2.9) and (AOR: 2.8, 95\% Cl: 1.7-4.8); and were exposed to environmental tobacco smoke (AOR: 1.6, 95\% Cl: 1.1-2.5) and (AOR: 1.9, 95\% Cl: 1.1-3.3) according to 'reversibility in $\mathrm{FEV}_{1}$ ' and 'respiratory symptoms and reversibility in $\mathrm{FEV}_{1}$ ', respectively. Asthmatics were more likely to report pack years of smoking $\geq 5$ (AOR: $2.3,95 \%$ Cl: 1.1-4.7) according to 'respiratory symptoms and reversibility in $\mathrm{FEV}_{1}$ '.

Conclusion: This study reports a high prevalence of asthma among Pakistani adults and calls for developing appropriate public health policies for prevention and control of asthma in the country. Further studies should be conducted to determine the national prevalence as well as follow-up studies to identify preventable causes for adult asthma.
\end{abstract}

Keywords: Asthma, Adult, Epidemiology, Risk factors, Spirometry, Pakistan

\section{Background}

According to available global estimates, around 300 million people currently suffer from asthma, which has become more common in adults in recent decades [1]. One in every 250 deaths worldwide has been attributed to asthma, which was found to rank 26th among causes associated with years of life lost in South Asia [1,2]. The increase in the prevalence of asthma has been associated with an increase in atopic sensitization, and is paralleled

\footnotetext{
* Correspondence: asaad.nafees@aku.edu

'Department of Community Health Sciences, Aga Khan University, Stadium Road, P.O. Box-3500, Karachi 74800, Pakistan

${ }^{5}$ Population Health and Occupational Disease, National Heart and Lung Institute (NHLI), Imperial College London, London, UK

Full list of author information is available at the end of the article
}

by similar increases in other allergic disorders such as eczema and rhinitis [1]. The rate of asthma increases as communities become more urbanized; with the projected increase in the proportion of the world's population that is urban from 45 to $59 \%$ in 2025 , there is likely to be a marked increase in the number of asthmatics worldwide [1].

The known risk factors for developing asthma include a combination of genetic predisposition and environmental exposure to various substances that may provoke allergic reactions or irritate the airways. Such environmental exposures may include house dust mites in bedding, carpets and stuffed furniture, pet dander, pollens and molds, tobacco smoke and chemical irritants

(c) The Author(s). 2018 Open Access This article is distributed under the terms of the Creative Commons Attribution 4.0 International License (http://creativecommons.org/licenses/by/4.0/), which permits unrestricted use, distribution, and reproduction in any medium, provided you give appropriate credit to the original author(s) and the source, provide a link to the Creative Commons license, and indicate if changes were made. The Creative Commons Public Domain Dedication waiver (http://creativecommons.org/publicdomain/zero/1.0/) applies to the data made available in this article, unless otherwise stated. 
$[3,4]$. Some additional factors which may exacerbate or cause asthma include work related stress, sedentary lifestyle and indoor air pollutants [5].

Globally, there is a lack of standardized data regarding prevalence of asthma due to variations in the operational definition and assessment techniques [6]. There is a lack of community based studies identifying burden of asthma through spirometry, while most of the studies rely on questionnaires $[5,7,8]$. The question regarding self-reported physician diagnosed asthma has been shown to have high specificity for assessing asthma in several epidemiological surveys worldwide, however, sizeable proportion of asthma may still remain undiagnosed [9]. In order to address this concern, the recent guidelines recommend a combination of questionnaire and spirometry based information as the best method for determining asthma in epidemiological surveys $[6,10]$.

According to India's National Family Health Survey, prevalence of adult self-reported asthma was around $1.8 \%$ [11]. Asthma prevalence has been found to vary from 0.7 to $11.9 \%$ across Asia, but the definitions used to identify asthma also varied extensively [5]. The report on global burden of asthma estimated the prevalence of asthma, in Pakistan to be 4.3\% [1]. Employing a robust methodology and using comprehensive set of definitions, this study was conducted in order to determine the prevalence of asthma and associated risk factors in the adult population of Karachi, Pakistan.

\section{Methods}

\section{Study design and setting}

This population based cross-sectional survey was conducted in Karachi, Pakistan, from May 2014 to August 2015. A megacity, and the largest urban center and economic hub of Pakistan, Karachi is estimated to have a population of over 20 million [12]. The city inhabits a mix of various regional and national ethno-linguistic groups while Urdu is the most commonly spoken language [13]. There are an estimated 702 slums in the city harboring $40-61 \%$ of the population [13]. The city is administratively divided into six districts; South, East, West, Central, Malir and Korangi; in addition, there are six military cantonments [12].

\section{Participant recruitment}

Multi-stage cluster sampling was used for selection of clusters (primary sampling units) and households (secondary sampling units) in Karachi. Using the sampling frame for clusters or enumeration blocks available from the Pakistan Bureau of Statistics (PBS) (2003), 75 clusters, out of 9400, were randomly selected. Line-listing was carried out within each cluster and 40 households per cluster (out of 250-300) were selected randomly. All eligible participants (adults aged $\geq 18$ years and those living in Karachi in the same household for at least six months) from the selected households were recruited in the study.

The required sample size was calculated to be 1284 participants (using the Open Epi version 2.3) based on prevalence of asthma assessed through spirometry $2 \%$ to $3.6 \%$ [14], or self-reported $2 \%$ to $6.5 \%$ [15], keeping bound on the error $1.5 \%$ and $2 \%$ respectively, confidence level of $95 \%$, a design effect of 2 and inflated by $10 \%$ to adjust for non-response and unacceptable quality of spirometry.

\section{Interviews}

Interviews were conducted in the local language by trained field staff using a structured questionnaire that was developed by adapting already published questionnaires for identifying possible risk factors of asthma [16]. It included questions related to the socio-demographic and economic variables (age, gender, socio-economic and educational status); indoor air pollution and ventilation (exposure to environmental tobacco smoke, housing structure, ventilation in house, kitchen characteristics and cooking habits) and other risk factors for asthma (presence of carpet at home, use of air-conditioning or incense and mosquito coils, recent paint or new furniture being brought at home and presence of pets, birds or animals at home). Questions regarding respiratory symptoms and illnesses (cough, sputum, wheeze, shortness of breath and any pre-existing respiratory conditions) including asthma, family history of asthma and other respiratory diseases, smoking habits, and occupation were added from the American Thoracic Society (ATS-DLD-78A) questionnaire, which has been validated in Pakistan [17, 18]. Questionnaire was translated into Urdu and then back translated to English to check the accuracy of translation and pre-tested before use.

\section{Lung function and anthropometric assessment}

Lung function was assessed through spirometry by trained field staff using Vitalograph Alpha spirometer (Vitalograph New Alpha 6000; Vitalograph Ltd., Buckingham, England) according to the ATS guidelines $[19,20]$. Participants were explained about the procedure and spirometry was performed in a sitting position with nose clip attached. Forced Vital Capacity (FVC), Forced Expiratory Volume in first second $\left(\mathrm{FEV}_{1}\right)$ and $\mathrm{FEV}_{1} / \mathrm{FVC}$ were recorded in liters. Post-bronchodilator reversibility in $\mathrm{FEV}_{1}$ was assessed by administering Salbutamol $(200 \mu \mathrm{g})$ through a 500-mL spacer device and repeating the test after 15 min. Three manoeuvers were performed and acceptable readings were recorded for both pre and post-bronchodilator response. Participants reporting eye, heart, lung, chest or abdominal surgery in the past 6 months, heart attack in the past 3 months, 
those with pulse greater than 120 beats per minute, recent respiratory infections (tuberculosis or pneumonia) and those who were pregnant at the time of data collection were excluded from performing spirometry. Anthropometric measurements including height and weight were also taken.

\section{Definitions}

Three distinct definitions for asthma were used; including 'self-reported, physician-diagnosed asthma' based on information from the questionnaire; 'reversibility in $\mathrm{FEV}_{1}$, assessed on presence of post-bronchodilator reversibility $\geq 200 \mathrm{ml}$ in $\mathrm{FEV}_{1}$; 'respiratory symptom(s) and reversibility in $\mathrm{FEV}_{1}$, , based on post-bronchodilator reversibility $\geq 200 \mathrm{ml}$ in $\mathrm{FEV}_{1}$ and one or more respiratory symptoms, or self-reported asthma [10]. 'Acute cough or phlegm' was defined as cough or phlegm as much as 4 to 6 times a day in a week and/or first thing in morning and/or at all during the rest of the day or at night. 'Chronic cough or phlegm' was defined as cough or phlegm for at least 3 consecutive months a year, for at least 2 years. 'Chronic wheeze' was defined as whistling sounds from chest (with or without cold), for at least 2 years. Shortness of breath was defined according to the Medical Research Council breathlessness scale which represent a spectrum of respiratory disability based on severity ranging from grade 1 to grade 5 [21]. Socio-economic status was defined using the proxy indicator of average monthly household income, which included income of all members living in the same house as well as additional earnings based on any business or other investment. 'Ever smoker' was defined as smoking more than 20 pack of cigarettes in lifetime or more than one cigarette a day for one year. 'Pack years of smoking' was defined as the number of cigarettes smoked per day divided by 20 and multiplied by the number of years that the person smoked. The variable 'ethnicity' was defined and categorized on the basis of five commonly spoken languages in Pakistan where minor variants and less commonly spoken dialects were merged with the more commonly spoken ones. For 'educational level' those who never attended school or did not know how to read or write were considered as illiterate while those who had been to school were categorized as literate. For the variable 'type of cluster'; planned areas included those with permanent housing structure, sufficient living place, access to safe water and adequate sanitation system, while unplanned areas were densely populated areas of substandard housing, characterized by poverty, unsanitary and inferior living conditions and social disorganization [22]. 'Animal or birds inside the house' included both pets as well as animals kept as livestock. Type of kitchen was categorized based on its location, either inside or outside the house. Type of household was categorized based on construction of the household; pakka house refers to brick dwelling or concrete, Kaccha-pakka house refers to a mix of mud or thatched and brick dwelling. 'Exposure to environmental tobacco smoke' was defined as being exposed to cigarette smoke anywhere inside the house. Body mass index was defined according to WHO criteria for Asian population and categorized as: underweighted, $<18.5 \mathrm{~kg} / \mathrm{m}^{2}$; normal, $18.5-23 \mathrm{~kg} / \mathrm{m}^{2}$; overweight and obese, $\geq 23 \mathrm{~kg} / \mathrm{m}^{2}$ [23]. 'Current employment status' was categorized as currently employed or self-employed and unemployed (included students, housewives, those currently not working anywhere or retired). The International Standard Classification of Occupations (ISCO) categories were grouped into three i.e. not working, high and low skilled blue collar workers (involved in manual work), high and low skilled white collar workers (involved in desk work) [24].

\section{Statistical methods}

Data were entered twice and validated through Epi Data version 3.1 while analysis was done using SPSS version 19.0. Frequencies and proportions were calculated for categorical variables including the covariates listed above, as well as the respiratory symptoms and outcome variables based on the three definitions of asthma. Chi-square test was done to assess distribution of participants according to asthma outcome status. The age of the participant was categorized considering ten year interval from age 18 years and older; three categories were used where those aged 38 years or older were merged together. The variable pack-years of smoking was re-categorized to adjust for small cell count into three categories for multivariate analysis. Multi-collinearity was assessed using Eta, Phi and Cramer tests between covariates (cut off value $>0.5$ ) and high collinearity was identified between gender and cooking status, as well as gender and occupational history. Interaction was checked between family history of asthma and history of allergies but it was not significant. The continuous variable of socio-economic status was categorized into tertiles and association was checked with outcome variables in univariate and multivariate models. Univariate logistic regression analysis was done to calculate unadjusted odds ratio of factors associated with two outcome variables; 'reversibility in $\mathrm{EFV}_{1}$ ' and 'respiratory symptoms and reversibility in $\mathrm{EFV}_{1}$ '. For the outcome defined as 'self-reported asthma', adjusted analysis could not be performed due to small proportion of asthmatics. The variables found to be significant in univariate models ( $p$-value $<0.25)$ and those with biological plausibility were assessed further in the multivariate models. For covariates with more than two categories the cut-off of $p$-value $<0.25$ was used for any one of the categories. Multivariate logistic regression was 
carried out to estimate the adjusted odds ratios for associated factors of asthma.

Ethical approval for the study was taken from Ethical Review Committee of Aga Khan University (2311-CHS-ERC-12). Prior to the interview, written informed consent was obtained from each respondent. The purpose and nature of the study was explained and spirometry procedure was demonstrated. Participants identified with any abnormality on spirometry were provided the report and were counselled and referred for further work-up and management.

\section{Results}

Approximately 3000 adults aged 18 years and above were contacted to participate in the study in the selected households, out of which 1629 agreed to participate; giving a response rate of around 55\%. Most of the non-responses were due to permanent relocation, or untraceable addresses and contact details. Participants who completed post-bronchodilator spirometry were 1054 and for those 930 spirograms were found to be acceptable according to standard guidelines. Majority (43\%) of the participants belonged to the age group $\geq 38$ years. Most common ethnicity among study participants was Urdu (44.6\%) and majority of the participants were females (60\%). Most of the study participants were currently unemployed (includes students, housewives, those currently not working anywhere or retired) (61\%), while $20 \%$ were blue collar workers and $18.5 \%$ were white collar workers according to ISCO categories and $27 \%$ reported exposure to a dusty job. Ever smokers in our study were $13.5 \%$ while $28 \%$ reported exposure to environmental tobacco smoke. History of any allergy was reported by $28 \%$ while $12 \%$ reported positive family history of asthma (Table 1).

The prevalence of self-reported asthma was 1.8\% (95\% CI: 1.0-2.6), while prevalence according to reversibility in $\mathrm{FEV}_{1}$ was $11.3 \%$ (95\% CI: 9.4-13.3) and symptoms and reversibility in $\mathrm{FEV}_{1}$ was $6.6 \%$ (95\% CI: 5.1-8.1) (Table 2). The break-up by sex (female/male) was: self-reported asthma: $1.6 \% / 2.0 \%$, reversibility in $\mathrm{FEV}_{1}$ : $10.8 \% / 11.7 \%$ and symptoms and reversibility in $\mathrm{FEV}_{1}$ : $6.9 \% / 6.2 \%$.

Among those with self-reported asthma $(n=29)$, common triggering factors for aggravation of asthma included; exposure to smoke (83\%), strong smell (53\%) and dust (83\%). Participants currently on prescribed medications for asthma were $80 \%$ and out of these $71 \%$ participants were taking inhaled bronchodilators whereas $42 \%$ were on oral medications.

The prevalence of respiratory symptoms identified in this study was: acute cough, $4.4 \%$ (95\% CI: 3.1-5.7); acute wheeze, $10.1 \%$ (95\% CI: 8.2-11.9); and shortness of breath (Grade I), 25.2\% (95\% CI: 22.5-27.9) (Table 2).
Various factors found to be associated with self-reported asthma include: age $\geq 38$ years; presence of two or more rooms in house; living in a Kacha-Pakka house; pack years of smoking for $\geq 20$ years; history of any allergy and family history of asthma (see Additional file 1).

Univariate logistic regression analysis found that asthmatics based on reversibility in $\mathrm{FEV}_{1}$ were more likely to belong to the age group $\geq 38$ years (OR 1.9, 95\% CI: 1.1 to 3.2 ), low socio-economic status (OR 1.8, 95\% CI: 1.1 to 3.1 ), were ever smokers (OR 1.6, 95\% CI: 1.1 to 2.6), and those with pack years of smoking of 5 years or more (OR 2.2, 95\% CI: 1.2 to 4.1) and those with history of any allergy (OR 1.7, 95\% CI: 1.1 to 2.6). Asthmatics according to respiratory symptoms and reversibility in $\mathrm{FEV}_{1}$ were more likely to belong to the age group $\geq 38$ years (OR 2.2, 95\% CI: 1.1 to 4.2), were illiterate (OR 1.9, $95 \% \mathrm{CI}: 1.1$ to 3.2 ), were among those with pack years of smoking of 5 years or more (OR 3.2, 95\% CI: 1.7 to 6.3), had exposure to environmental tobacco smoke (OR 1.8, 95\% CI: 1.1 to 3.1), had history of allergies (OR 2.7, $95 \%$ CI: 1.6 to 4.5 ) and had family history of asthma (OR 2.0, 95\% CI: 1.1 to 3.9) (Table 3).

Multivariate logistic regression models found that participants categorized as asthmatics on reversibility in $\mathrm{FEV}_{1}$ were more likely to belong to the age group $\geq 38$ years (AOR 1.9, 95\% CI: 1.2 to 3.3), low socioeconomic group (AOR 1.9, 95\% CI: 1.2 to 3.4), to have history of allergies (AOR 1.9, 95\% CI: 1.2 to 2.9 ), exposure to environmental tobacco smoke (AOR 1.6, 95\% CI: 1.1 to $2.5)$. While asthmatics based on respiratory symptoms and reversibility in $\mathrm{FEV}_{1}$ were more likely belong to age group $\geq 38$ years (AOR 2.1, 95\% CI: 1.1 to 4.2), reported 5 or more pack years of smoking (AOR 2.3, 95\% CI: 1.1 to 4.7), reported exposure to environmental tobacco smoke (AOR 1.9, 95\% CI: 1.1 to 3.3) and had history of any allergy (AOR 2.8, 95\% CI: 1.7 to 4.8 ) (Table 4).

\section{Discussion}

To the best of our knowledge, this is the first community-based epidemiological assessment identifying prevalence of adult asthma in Pakistan. Globally, there is a lack of reliable estimates for asthma and a lack of agreement on standardized criteria for epidemiological assessment of asthma and therefore we believe that this study fills an important gap in knowledge by providing reliable estimates on adult asthma using a combination of respiratory symptoms and objective assessment. This study found significant unreported asthma with the use of spirometry in the city of Karachi, Pakistan; 11.3 and $6.6 \%$ for 'reversibility in $\mathrm{FEV}_{1}$ ' and 'respiratory symptoms and reversibility in $\mathrm{FEV}_{1}$ ' respectively; while reporting comparatively lower prevalence (1.8\%) for self-reported asthma. 
Table 1 Socio-demographic, anthropometric, household, lifestyle and occupational factors among adults $\geq 18$ years, Karachi, Pakistan $(n=1629)$

\begin{tabular}{ll}
\hline Characteristics & $n(\%)$ \\
\hline Age
\end{tabular}

$$
\begin{aligned}
& 18 \text { to } 27 \text { years } \\
& 28 \text { to } 37 \text { years } \\
& \geq 38 \text { years }
\end{aligned}
$$

$699(42.9)$

Gender

$$
\text { Male }
$$$$
\text { Female }
$$$$
\text { Birth Order }
$$$$
1 \text { st }
$$$$
\text { 2nd }
$$$$
3 r d
$$$$
\geq 4 \text { th }
$$

Total number of children in household

$$
\begin{aligned}
& 1 \text { to } 3 \\
& 4 \text { to } 5
\end{aligned}
$$$$
\geq 6
$$

Ethnicity

$$
\begin{aligned}
& \text { Urdu } \\
& \text { Punjabi } \\
& \text { Sindhi } \\
& \text { Pushto } \\
& \text { Baluchi }
\end{aligned}
$$

Educational level ${ }^{a}(n=1626)$

$$
\begin{aligned}
& \text { Literate } \\
& \text { Illiterate }
\end{aligned}
$$

Socio-economic status ${ }^{\mathrm{b}}(n=1621)$

High-income

Middle-income

Low-income

Number of rooms in house

$$
1 \text { room }
$$

$$
\geq 2 \text { rooms }
$$

House ownership status

Own

Rented

Type of household

Pakka

Kacha-Pakka

Type of cluster ${ }^{c}$

Planned

Unplanned

$394(24.2)$

$310(19.0)$

$295(18.1)$

$232(14.3)$

$442(27.1)$

$955(58.6)$

715 (43.9)

469 (28.8)

295 (18.1)

$90(5.5)$

60 (3.7)

1109 (68.2)

$517(31.8)$

537 (33.0)

$540(33.1)$

$293(18.0)$

$1336(82.0)$

$1579(97.0)$

$855(52.5)$
Table 1 Socio-demographic, anthropometric, household, lifestyle and occupational factors among adults $\geq 18$ years, Karachi, Pakistan ( $n=1629)$ (Continued)

\begin{tabular}{ll}
\hline Characteristics & $n(\%)$ \\
\hline Wet spots inside house & $844(51.8)$ \\
Mold Inside house & $81(5.0)$ \\
Animal or birds inside house $^{d}$ & $474(29.0)$ \\
Carpeting inside house & $528(32.4)$ \\
Incense burning in house & $767(47.1)$ \\
Mosquito coil burning in house & $739(45.4)$ \\
Painted home in last 6 months & $204(12.5)$ \\
Cook food & $894(54.9)$ \\
Frequency of cooking food &
\end{tabular}

No cooking at all

$735(45.1)$

Occasionally

$143(8.8)$

Daily

Presence of window in kitchen

Presence of exhaust fan in kitchen

$227(13.9)$

Type of kitchen

Outdoor

$632(38.7)$

Indoor separate

$268(16.5)$

Indoor non-separate

$729(44.8)$

Smoking status ${ }^{e}$

Never

1409 (86.5)

Ever

$220(13.5)$

Pack years of smoking ${ }^{f}$

Non smoker

1409 (86.5)

$\leq 10$

$132(8.1)$

$10-20$

$31(1.9)$

$>20$

$57(3.5)$

$452(28.1)$

Exposure to environmental tobacco smoke ${ }^{g}$

$673(41.8)$

Body Mass Index $(n=1611)$

Underweight

$575(35.7)$

Normal weight

$363(22.5)$

Overweight and obese

$451(27.7)$

$192(11.8)$

Family history of asthma

$44(2.7)$

1223 (75.1) Family History of tuberculosis

899 (55.2)

Never worked

$293(18.0)$

Working and no dust exposure

437 (26.8)

Working and dust exposure

899 (55.2)

Exposure to gas or fumes at work

Never worked

$592(36.3)$

Working and no gas exposure

$138(8.5)$ 
Table 1 Socio-demographic, anthropometric, household, lifestyle and occupational factors among adults $\geq 18$ years, Karachi, Pakistan $(n=1629)$ (Continued)

\begin{tabular}{ll}
\hline Characteristics & $n(\%)$ \\
\hline Current employment status & \\
Unemployed & $1000(61.4)$ \\
Employed & $629(38.6)$ \\
ISCO Categories & \\
Not working & $1000(61.4)$ \\
White collar worker & $301(18.5)$ \\
Blue collar worker & $328(20.1)$ \\
\hline
\end{tabular}

${ }^{a}$ Educational level: those who never attended school or did not know how to read or write were considered as illiterate while those who had been to school were categorized as literate

${ }^{\mathrm{b}}$ Socio-economic status was defined using the proxy indicator of monthly household income which included income of all members living in the same house as well as additional earnings based on any business or other investment 'Type of cluster was defined as planned areas included those with permanent housing structure, sufficient living place, access to safe water and adequate sanitation system, while unplanned areas were densely populated areas of substandard housing, characterized by poverty, unsanitary and inferior living conditions and social disorganization

${ }^{\mathrm{d}}$ Animal or birds inside house included both pets as well as animals kept as livestock

${ }^{\mathrm{e}}$ Ever smoker was defined as smoking more than 20 packs of cigarettes in a lifetime or more than one cigarette a day for one year

fPack years of smoking was defined as the number of cigarettes smoked per day divided by 20 and multiplied by the number of years that the person smoked

${ }^{9}$ Exposure to environmental tobacco smoke was defined as anyone who smoked cigarettes anywhere inside the house

${ }^{\text {h}}$ Body mass index was defined according to $\mathrm{WHO}$ criteria for Asian population and categorized as: underweighted, $<18.5 \mathrm{~kg} / \mathrm{m}^{2} ;$ normal, $18.5-23 \mathrm{~kg} / \mathrm{m} 2 ;$ overweight and obese, $\geq 23 \mathrm{~kg} / \mathrm{m}^{2}$

'Current employment status was defined as employed somewhere currently or self-employed, whereas, unemployed included students, housewives, those currently not working anywhere or retired

'The International Standard Classification of Occupations (ISCO) categories were three i.e. not working, high and low skilled blue collar workers (involved in manual work), high and low skilled white collar workers (involved in desk work)
Prevalence of self-reported asthma (1.8\%) in this study was comparable to regional estimates; approximately $2 \%$ in India and Thailand $[7,14]$. In the Indian INSEARCH survey, self-reported asthma was diagnosed based on asthma symptoms, previous diagnosis of asthma or medication use [7]. Whereas, the survey from Thailand also identified asthma based on self-reported physician diagnosed asthma accompanied by any asthma symptoms or use of medications [14]. However, our study estimate was lower than that reported by a national survey in Iran, using symptoms of wheezing with dyspnea, as 9.4\%; and also somewhat lower when using their definition of 'current asthma' which included asthma attack or use of asthma medications i.e. 4.7\% [8]. Obel et al. reported asthma burden to be $6.9 \%$ in a population based survey from sub-Saharan Africa using self-reported asthma-ever and and/or receiving asthma medications, which is higher than in our study [25]. Furthermore, South Asian women including those of Pakistani origin living in the United Kingdom were found to have a self-reported asthma prevalence of $10.9 \%$ [15]. Some of these differences are due to the use of varying definitions for asthma while the study from the UK may reflect an additional risk of asthma among migrants from South Asian countries. The use of the variable physician-diagnosed asthma may also be unreliable due to the varying capacity of general practitioners to identify asthma in different countries [6].

Prevalence of asthma based on reversibility in $\mathrm{FEV}_{1}$ was $11.3 \%$ in this study, which is comparable to prevalence reported from Iran of 9.4\% [26]. We believe that our study identified a previously unreported burden of asthma through spirometry. Though this is a robust and objective assessment, spirometry may still underestimate

Table 2 Prevalence of asthma and respiratory symptoms among adults $\geq 18$ years, Karachi, Pakistan, $2015(n=1629)$

\begin{tabular}{lll}
\hline Outcome variables & $n(\%)$ & $95 \% \mathrm{Cl}$ \\
\hline Self-reported asthma ${ }^{\text {a }}$ & $29(1.8)$ & $1.0-2.6$ \\
Reversibility $\geq 200 \mathrm{ml}$ in FEV ${ }_{1}^{\text {b d }}$ & $105(11.3)$ & $9.4-13.3$ \\
Respiratory symptoms and reversibility $\geq 200 \mathrm{ml} \mathrm{in} \mathrm{FEV}_{1}^{\mathrm{Cd}}$ & $61(6.6)$ & $5.1-8.1$ \\
SOB grade I & $410(25.2)$ & $22.5-27.9$ \\
SOB grade II & $359(22.0)$ & $19.5-24.6$ \\
Acute cough & $72(4.4)$ & $3.1-5.7$ \\
Chronic cough & $49(3.0)$ & $1.9-4.1$ \\
Acute wheeze & $164(10.1)$ & $8.2-11.9$ \\
Chronic wheeze & $130(8.0)$ & $6.3-9.7$ \\
Acute phlegm & $107(6.6)$ & $5.1-8.1$ \\
Chronic phlegm & $60(3.7)$ & $2.5-4.9$ \\
\hline
\end{tabular}

${ }^{\mathrm{d}}$ Sample size: 930 participants

SOB Shortness of breath

${ }^{a}$ Self-reported, physician-diagnosed asthma

${ }^{\mathrm{b}}$ Spirometry-based asthma assessed on presence of post-bronchodilator reversibility $\geq 200 \mathrm{ml}$ in FEV

'Asthma based on post-bronchodilator reversibility $\geq 200 \mathrm{ml}$ in FEV ${ }_{1}$ and one or more respiratory symptoms, or self-reported asthma 
Table 3 Univariate logistic regression analysis for factors associated with asthma among adults $\geq 18$ years, Karachi, Pakistan ( $n=930$ )

\begin{tabular}{|c|c|c|c|c|}
\hline \multirow[t]{2}{*}{ Characteristics } & \multicolumn{2}{|c|}{ Reversibility in $\mathrm{FEV}_{1}{ }^{\mathrm{k}}$} & \multicolumn{2}{|c|}{ Respiratory symptoms and reversibility in $\mathrm{FEV}_{1}{ }^{\mathrm{k}}$} \\
\hline & OR $(95 \% \mathrm{Cl})$ & $P$-Value & OR $(95 \% \mathrm{Cl})$ & $p$-value \\
\hline \multicolumn{5}{|l|}{ Age } \\
\hline 18 to 27 years & 1 & 0.02 & 1 & 0.01 \\
\hline 28 to 37 years & $0.9(0.5-1.8)$ & 0.51 & $0.7(0.3-1.8)$ & 0.47 \\
\hline$\geq 38$ years & $1.9(1.1-3.2)$ & 0.03 & $2.2(1.1-4.2)$ & 0.02 \\
\hline \multicolumn{5}{|l|}{ Gender } \\
\hline Male & 1 & & 1 & \\
\hline Female & $0.9(0.6-1.4)$ & 0.40 & $1.1(0.7-1.9)$ & 0.64 \\
\hline \multicolumn{5}{|l|}{ Birth Order } \\
\hline 1 st & $0.8(0.5-1.5)$ & 0.51 & $0.8(0.4-1.6)$ & 0.48 \\
\hline 2nd & $0.9(0.6-1.7)$ & 0.61 & $0.8(0.4-1.8)$ & 0.67 \\
\hline $3 r d$ & $1.0(0.6-1.8)$ & 0.31 & $1.4(0.7-2.7)$ & 0.37 \\
\hline$\geq 4$ th & 1 & & 1 & \\
\hline \multicolumn{5}{|c|}{ Total number of Children } \\
\hline 1 to 3 & $0.9(0.5-1.6)$ & 0.22 & $0.9(0.5-1.7)$ & 0.21 \\
\hline 4 to 5 & $0.9(0.5-1.4)$ & 0.81 & $0.5(0.2-1.4)$ & 0.82 \\
\hline$\geq 6$ & 1 & & 1 & 0.44 \\
\hline \multicolumn{5}{|l|}{ Education $^{a}$} \\
\hline Literate & 1 & & 1 & \\
\hline Illiterate & $1.4(0.9-2.1)$ & 0.05 & $1.9(1.1-3.2)$ & 0.02 \\
\hline \multicolumn{5}{|c|}{ Socio-economic status ${ }^{\mathrm{b}}$} \\
\hline High income & 1 & 0.21 & 1 & 0.13 \\
\hline Middle income & $1.6(0.9-2.6)$ & 0.10 & $0.9(0.5-1.7)$ & 0.22 \\
\hline Low income & $1.8(1.1-3.1)$ & 0.03 & $1.2(0.6-2.2)$ & 0.24 \\
\hline \multicolumn{5}{|l|}{ Number of rooms } \\
\hline$\geq 2$ rooms & 1 & & 1 & \\
\hline 1 room & $1.1(0.7-1.8)$ & 0.75 & $1.1(0.6-2.2)$ & 0.71 \\
\hline \multicolumn{5}{|l|}{ Ownership status } \\
\hline Own & 1 & & 1 & \\
\hline Rented & $0.9(0.6-1.5)$ & 0.31 & $1.3(0.7-2.2)$ & 0.44 \\
\hline \multicolumn{5}{|l|}{ Type of cluster ${ }^{c}$} \\
\hline Planned & 1 & & 1 & \\
\hline Unplanned & $1.0(0.7-1.6)$ & 0.29 & $0.9(0.5-1.5)$ & 0.73 \\
\hline \multicolumn{5}{|c|}{ Wet spots inside house } \\
\hline No & 1 & & 1 & \\
\hline Yes & $1.1(0.7-1.6)$ & 0.28 & $0.9(0.6-1.7)$ & 0.99 \\
\hline \multicolumn{5}{|c|}{ Animal or birds inside house ${ }^{d}$} \\
\hline No & 1 & & 1 & \\
\hline Yes & $0.7(0.4-1.2)$ & 0.19 & $0.6(0.3-1.1)$ & 0.10 \\
\hline \multicolumn{5}{|c|}{ Carpeting inside house } \\
\hline No & 1 & & 1 & \\
\hline Yes & $0.9(0.6-1.4)$ & 0.81 & $0.9(0.6-1.7)$ & 0.88 \\
\hline
\end{tabular}


Table 3 Univariate logistic regression analysis for factors associated with asthma among adults $\geq 18$ years, Karachi, Pakistan ( $n=930$ ) (Continued)

\begin{tabular}{|c|c|c|c|c|}
\hline \multirow[t]{2}{*}{ Characteristics } & \multicolumn{2}{|c|}{ Reversibility in $\mathrm{FEV}_{1}{ }^{\mathrm{k}}$} & \multicolumn{2}{|c|}{ Respiratory symptoms and reversibility in $\mathrm{FEV}_{1}$} \\
\hline & $\mathrm{OR}(95 \% \mathrm{Cl})$ & $P$-Value & $\mathrm{OR}(95 \% \mathrm{Cl})$ & $p$-value \\
\hline \multicolumn{5}{|l|}{ Incense burning in home } \\
\hline Never & 1 & & 1 & \\
\hline Ever & $1.0(0.7-1.5)$ & 0.96 & $1.0(0.6-1.7)$ & 0.97 \\
\hline \multicolumn{5}{|l|}{ Mosquito coil } \\
\hline Never & 1 & & 1 & \\
\hline Ever & $0.7(0.5-1.1)$ & 0.85 & $0.9(0.6-1.6)$ & 0.91 \\
\hline \multicolumn{5}{|l|}{ Cooking food } \\
\hline No & 1 & & 1 & \\
\hline Yes & $1.0(0.7-1.5)$ & 0.41 & $0.5(0.3-1.1)$ & 0.47 \\
\hline \multicolumn{5}{|l|}{ Window in Kitchen } \\
\hline Yes & 1 & & 1 & \\
\hline No & $0.9(0.6-1.3)$ & 0.08 & $0.6(0.4-1.0)$ & 0.05 \\
\hline \multicolumn{5}{|l|}{ Exhaust in kitchen } \\
\hline Yes & 1 & & 1 & \\
\hline No & $0.8(0.5-1.5)$ & 0.51 & $0.5(0.3-0.9)$ & 0.04 \\
\hline \multicolumn{5}{|l|}{ Type of kitchen } \\
\hline Outdoor & 1 & & 1 & 0.401 \\
\hline Indoor separate & $1.5(0.8-2.6)$ & 0.15 & $1.6(0.8-3.4)$ & 0.17 \\
\hline Indoor non separate & $1.2(0.7-1.9)$ & 0.21 & $1.3(0.7-2.4)$ & 0.41 \\
\hline \multicolumn{5}{|l|}{ Smoking status ${ }^{\mathrm{e}}$} \\
\hline Never & 1 & & 1 & \\
\hline Ever & $1.6(1.1-2.6)$ & 0.03 & $1.7(0.9-3.1)$ & 0.07 \\
\hline \multicolumn{5}{|l|}{ Pack years of smoking ${ }^{f}$} \\
\hline Non smoker & 1 & 0.00 & 1 & 0.001 \\
\hline$<5$ years & $1.1(0.5-2.4)$ & 0.39 & $0.6(0.2-2.1)$ & 0.47 \\
\hline$\geq 5$ years & $2.2(1.2-4.1)$ & 0.001 & $3.2(1.7-6.3)$ & 0.001 \\
\hline \multicolumn{5}{|c|}{ Exposure to environmental tobacco smoke $\mathrm{g}^{\mathrm{g}}$} \\
\hline No & 1 & & 1 & \\
\hline Yes & $1.5(0.9-2.3)$ & 0.05 & $1.8(1.1-3.1)$ & 0.03 \\
\hline \multicolumn{5}{|l|}{ Body Mass Index ${ }^{\mathrm{h}}$} \\
\hline Underweight & 1 & 0.490 & 1 & 0.410 \\
\hline Normal & $1.4(0.9-2.2)$ & 0.100 & $1.4(0.8-2.6)$ & 0.287 \\
\hline Overweight and obese & $1.3(0.8-2.3)$ & 0.101 & $1.6(0.8-3.1)$ & 0.208 \\
\hline \multicolumn{5}{|l|}{ History of any allergy } \\
\hline No & 1 & & 1 & \\
\hline Yes & $1.7(1.1-2.6)$ & 0.02 & $2.7(1.6-4.5)$ & 0.001 \\
\hline \multicolumn{5}{|l|}{ Family history of asthma } \\
\hline No & 1 & & 1 & \\
\hline Yes & $1.0(0.5-1.9)$ & 0.41 & $2.0(1.1-3.9)$ & 0.00 \\
\hline \multicolumn{5}{|l|}{ Exposure of dusty job } \\
\hline Not working & 1 & 0.81 & 1 & 0.82 \\
\hline Working and no dust exposure & $0.9(0.5-1.5)$ & 0.42 & $0.4(0.1-0.9)$ & 0.04 \\
\hline Working and dust exposure & $1.4(0.9-2.1)$ & 0.39 & $1.2(0.7-2.2)$ & 0.42 \\
\hline
\end{tabular}


Table 3 Univariate logistic regression analysis for factors associated with asthma among adults $\geq 18$ years, Karachi, Pakistan $(n=930)$ (Continued)

\begin{tabular}{|c|c|c|c|c|}
\hline \multirow[t]{2}{*}{ Characteristics } & \multicolumn{2}{|c|}{ Reversibility in $\mathrm{FEV}_{1}{ }^{\mathrm{k}}$} & \multicolumn{2}{|c|}{ Respiratory symptoms and reversibility in $\mathrm{FEV}_{1}{ }^{\mathrm{k}}$} \\
\hline & OR $(95 \% \mathrm{Cl})$ & $P$-Value & OR $(95 \% \mathrm{Cl})$ & $p$-value \\
\hline \multicolumn{5}{|l|}{ Exposure of gas or fumes at work } \\
\hline Not working & 1 & 0.10 & 1 & 0.91 \\
\hline Working and no gas exposure & $1.1(0.7-1.7)$ & 0.41 & $0.9(0.5-1.6)$ & 0.68 \\
\hline Working and gas exposure & $1.5(0.8-2.8)$ & 0.35 & $0.9(0.4-2.3)$ & 0.97 \\
\hline \multicolumn{5}{|l|}{ Current employment status' } \\
\hline Unemployed & 1 & & 1 & \\
\hline Employed & $1.1(0.7-1.7)$ & 0.51 & $0.9(0.5-1.5)$ & 0.701 \\
\hline \multicolumn{5}{|l|}{ ISCO Categories ${ }^{j}$} \\
\hline Not working & 1 & 0.78 & 1 & 0.88 \\
\hline White collar worker & $0.9(0.5-1.5)$ & 0.59 & $0.8(0.4-1.7)$ & 0.62 \\
\hline Blue collar worker & $1.3(0.8-2.1)$ & 0.34 & $0.95(0.5-1.8)$ & 0.87 \\
\hline
\end{tabular}

${ }^{a}$ Educational level: those who never attended school or did not know how to read or write were considered as illiterate while those who had been to school were categorized as literate

${ }^{b}$ Socio-economic status was defined using the proxy indicator of monthly household income which included income of all members living in the same house as well as additional earnings based on any business or other investment

'Type of cluster was defined as planned areas included those with permanent housing structure, sufficient living place, access to safe water and adequate sanitation system, while unplanned areas were densely populated areas of substandard housing, characterized by poverty, unsanitary and inferior living conditions and social disorganization

${ }^{\mathrm{d}}$ Animal or birds inside house included both pets as well as animals kept as livestock

ever smoker was defined as smoking more than 20 packs of cigarettes in a lifetime or more than one cigarette a day for one year

fPack years of smoking was defined as the number of cigarettes smoked per day divided by 20 and multiplied by the number of years that the person smoked

${ }^{9}$ Exposure to environmental tobacco smoke was defined as anyone who smoked cigarettes anywhere inside the house

hody mass index was defined according to WHO criteria for Asian population and categorized as: underweighted, < 18.5 kg/m2; normal, $18.5-23 \mathrm{~kg} / \mathrm{m}^{2}$; overweight and obese, $\geq 23 \mathrm{~kg} / \mathrm{m}^{2}$

'Current employment status was defined as employed somewhere currently or self-employed, whereas, unemployed included students, housewives, those currently not working anywhere or retired

'The International Standard Classification of Occupations (ISCO) categories were three i.e. not working, high and low skilled blue collar workers (involved in manual work), high and low skilled white collar workers (involved in desk work)

kDefinitions used for asthma:

Spirometry-based asthma assessed on presence of post-bronchodilator reversibility $\geq 200 \mathrm{ml}$ in FEV1

Asthma based on post-bronchodilator reversibility $\geq 200 \mathrm{ml}$ in FEV1 and one or more respiratory symptoms, or self-reported asthma

the actual prevalence of asthma due to the less sensitive nature of the reversibility test as compared to physicians' assessment [27]. There is a probability of people who fail to accomplish the reversibility criteria significantly on a single occasion but who actually have asthma [27].

Lower prevalence rates of 2.9 and $2.3 \%$ have been reported from Thailand and South Australia [14, 27], respectively. Whereas, prevalence found in our study was $6.6 \%$, comparatively higher based on respiratory symptoms and reversibility in $\mathrm{FEV}_{1}$. The study by Dejsomritrutai et al. among Thai adults was a community based survey which identified asthma on reversibility in spirometry or having any respiratory symptoms, in addition to bronchial hyper-responsiveness on bronchoprovocation test [14]. Furthermore, Amiri et al. reported 9\% prevalence from a cross-sectional survey from Iran where asthma assessed through spirometry [26]. De Marco et al. reported that asthma prevalence may be overestimated if assessed through self-reported wheezing but might be underestimated if assessed through self-reported asthma and clinical judgment [28]. Our study also supports the use of a combination of lung function and respiratory symptoms data for assessing asthma and identified a wide gap between self-reported asthma and substantial unidentified burden of asthma in the community.

Prevalence of acute and chronic wheeze reported in this study was 10 and $8 \%$ respectively, while prevalence of wheeze in past 12 months reported in a study from India was 2.6\% [7]. Prevalence for shortness of breath (Grade I) found in this study was $25 \%$, while prevalence of breathlessness on exertion was reported by $5 \%$ in India, which might be due to over-reporting in our study [7].

The prevalence of acute and chronic cough reported in our study was 4.4 and $3 \%$, respectively, which is comparable to the prevalence of chronic cough found in India, i.e. 4.6\% [7]. Prevalence of acute and chronic phlegm was found to be 6.6 and $3.7 \%$ respectively in this study which is also similar to $3.8 \%$ prevalence of chronic phlegm reported from India [7].

A study conducted in Mashhad, Iran, found that history of allergy was an important risk factor for asthma, a finding which is similar to our study which found history of allergy to be associated with asthma 
Table 4 Multivariate logistic regression analysis for factors associated with asthma among adults $\geq 18$ years, Karachi, Pakistan $(n=930)$

\begin{tabular}{|c|c|c|}
\hline Characteristics & Reversibility $\geq 200 \mathrm{ml}$ in $\mathrm{FEV}_{1}{ }^{\mathrm{k}}$ & Respiratory symptoms and reversibility in $\mathrm{FEV}_{1}{ }^{\mathrm{k}}$ \\
\hline & AOR $(95 \% \mathrm{Cl})$ & AOR $(95 \% \mathrm{Cl})$ \\
\hline \multicolumn{3}{|l|}{ Age } \\
\hline 18 to 27 years & 1 & 1 \\
\hline 28 to 37 years & $0.9(0.5-1.7)$ & $0.7(0.3-1.8)$ \\
\hline$\geq 38$ years & $1.9(1.2-3.3)$ & $2.1(1.1-4.2)$ \\
\hline \multicolumn{3}{|c|}{ Socio-economic status ${ }^{a}$} \\
\hline High income & 1 & - \\
\hline Middle income & $1.7(0.9-2.8)$ & - \\
\hline Low income & $1.9(1.2-3.4)$ & - \\
\hline \multicolumn{3}{|c|}{ History of any allergy } \\
\hline No & 1 & 1 \\
\hline Yes & $1.9(1.2-2.9)$ & $2.8(1.7-4.8)$ \\
\hline \multicolumn{3}{|c|}{ Pack years of smoking ${ }^{b}$} \\
\hline Non smoker & - & 1 \\
\hline$<5$ years & - & $0.6(0.2-1.9)$ \\
\hline$\geq 5$ years & - & $2.3(1.1-4.7)$ \\
\hline \multicolumn{3}{|c|}{ Exposure to environmental tobacco smoke ${ }^{c}$} \\
\hline No & 1 & 1 \\
\hline Yes & $1.6(1.1-2.5)$ & $1.9(1.1-3.3)$ \\
\hline
\end{tabular}

${ }^{a}$ Socio-economic status was defined using the proxy indicator of monthly household income which included income of all members living in the same house as well as additional earnings based on any business or other investment

${ }^{b}$ Pack years of smoking was defined as the number of cigarettes smoked per day divided by 20 and multiplied by the number of years that the person smoked

${ }^{c}$ Exposure to environmental tobacco smoke was defined as anyone who smoked cigarettes anywhere inside the house

kefinitions used for asthma:

Spirometry-based asthma assessed on presence of post-bronchodilator reversibility $\geq 200 \mathrm{ml}$ in $\mathrm{FEV}_{1}$

Asthma based on post-bronchodilator reversibility $\geq 200 \mathrm{ml}$ in $\mathrm{FEV}_{1}$ and one or more respiratory symptoms, or self-reported asthma

according to both definitions 'reversibility in $\mathrm{FEV}_{1}$ ' and 'respiratory symptoms and reversibility in $\mathrm{FEV}_{1}$ ' with odds ratio of AOR (95\% CI): 1.9 (1.2-2.9) and 2.8 (1.74.8) respectively. [29]. Allergy has been commonly reported risk factor across many studies and established associations have also been found for high Serum IgE level, a substitute for allergic sensitization, and for common allergens identified by skin prick tests with asthma $[3,30]$. A nationally representative survey among Iranian adults showed that prevalence of asthma was significantly higher among the older age group [8]. This finding is comparable to the INSEARCH survey from India which determined significant relationship with advancing age, highlighting a possible "cumulative effect" of age, including asthma diagnosed in past, besides late onset of the disease [7]. New onset asthma may also occur in adulthood because of prolonged environmental or occupational exposures to respiratory irritants [3]. High asthma prevalence has been observed progressively with increasing age in Asia [5]. Likewise, evidence suggests that older people with a history of smoking may develop asthma-COPD overlap syndrome (ACOS) [31]. People with COPD might have airway responsiveness, have shown reversibility in $\mathrm{FEV}_{1}$ and therefore may be categorized as ACOS. Such cases may have overestimated the prevalence in our study however, symptoms suggestive of asthma were also taken into account in one of the definitions in order to overcome such over-reporting [32].

Tobacco smoking is known to cause inflammatory changes of the airway tract, resulting in developing or worsening of pre-existing asthma symptoms; however, there is inconsistency of evidence regarding association of tobacco smoking and adult asthma [2, 33]. An Indian survey found smoking to be an important risk factor for asthma [11]. Further, Swedish studies reported population attributable risk for asthma symptoms attributed to smoking between 9.8 to $25.5 \%$ [33]. Recently, a follow up study suggested that smokers with asthma tend to have more complaint of chronic cough and phlegm as compared to non-smokers [34]. These findings are consistent with our study where we found an association between tobacco smoking and asthma according to "respiratory symptoms and reversibility in $\mathrm{FEV}_{1}$ " AOR (95\% CI): 2.3 (1.1-4.7).

Previous studies found that environmental tobacco smoke exposure, one of the consistent modifiable risk 
factor, played a strong role in developing and aggravating asthma [3, 35]. Our finding for environmental tobacco smoke AOR (95\% CI): $1.6(1.1-2.5)$ and 1.9 (1.1-3.3) respectively for definitions based on 'reversibility in $\mathrm{FEV}_{1}$ ' and 'respiratory symptoms and reversibility in $\mathrm{FEV}_{1}$ ' was consistent with other studies [3]. European Community Respiratory Health Survey (ECRHS) findings suggest that maternal smoking during pregnancy or post-natal period as well as paternal smoking is associated with development of symptoms suggestive of asthma and had detrimental effect on lung function of children later in the adulthood [36]. Socioeconomic position has an important role to be identified for preventing inequalities and overall decreasing disease burden [37]. In our study, significant association of lower socioeconomic status has been found with asthma AOR (95\% CI): 1.9 (1.2-2.9). This finding was consistent with a multicenter study which found low socio-economic position as a consistent risk factor for asthma [37]. Another cohort study reported association of lower socioeconomic position with the asthma onset in adulthood [38]. Our study could not find any significant association of asthma with gender, which is similar to findings of a population based study from Iran [8]. There is some inconsistent evidence suggesting possible role of hormonal changes during puberty for greater likelihood of asthma among women [39].

Some limitations need to be considered for this study. We had a relatively high non-response rate of $45 \%$ which may be attributed to a generally poor security situation in the city at the time of data collection, resulting in limited access for study teams. However, spirometry based surveys have been found to report low response rates, such as studies conducted in Thailand, Tanzania and Sweden [14, 40, 41]. Probable reasons for low participation in spirometry based surveys may include apprehensions for the spirometry procedure, which requires physical exertion. Since the study was conducted in urban setting, hence, generalizability may be limited to similar urban population in Pakistan. However, we believe that the population in Karachi represents common ethnic groups of the country; therefore our findings are applicable for various ethno-linguistic groups from urban areas of the country.

There are several strengths which need to be considered for this study as well. This was the first community based respiratory health survey conducted in Pakistan employing robust methodology and objective lung function assessment. This study used standard ATS guidelines and protocols for conducting spirometry for asthma assessment, along with WHO Global Health Survey based standard definitions of physician-diagnosed asthma [19, 20]. American Thoracic Society respiratory questionnaire (ATS-DLD-78A) was used in this study for assessment of respiratory symptoms, which has been validated both internationally and locally in Pakistan [17]. In addition, a sampling frame was developed prior to data collection for purpose of random selection of households which adds to the strengths of this study. We believe that this study would have a substantial research impact in terms of providing much needed empirical evidence related to respiratory epidemiology on prevalence of asthma in Pakistan via three different definitions. The information obtained from this study may be utilized for priority-setting and developing strategic public health plans for the optimal resource allocation for preventive and curative programs.

\section{Conclusion}

This study provides a robust community based epidemiological assessment for actual prevalence of adult asthma in Pakistan, reporting a high prevalence in the country. The study identified age $\geq 38$ years, low socio-economic status, history of allergies, exposure to environmental tobacco smoke and $\geq 5$ pack-years of smoking as important risk factors for adult asthma in the country. Our findings have strong implications for incorporating chronic respiratory diseases, including asthma, among priority non-communicable diseases in the national and regional health policies of the country, with adequate provision for both curative and preventive strategies.

\section{Additional file}

Additional file 1: Table S1. Frequency distribution of socio-demographic, anthropometric, household, lifestyle and occupational factors among adults $\geq 18$ years according to self-reported physician-diagnosed asthma, Karachi, Pakistan ( $n=1629)$. (DOCX $16 \mathrm{~kb}$ )

\section{Abbreviations}

AOR: Adjusted odds ratio; Cl: Confidence interval; $\mathrm{FEV}_{1}$ : Forced expiratory volume in first second; FVC: Forced Vital Capacity

\section{Acknowledgements}

We are thankful to Dr. Muhammad Masood Kadir and Mr. Mehboob John for facilitation in the line listing process for this study. We would also like to thank Mr. Waqas Ahmed, Ms. Shaista Khan, Dr. Neelum Jamal, Dr. Saima Muneer, Dr. Raheel Mehran, Mr. Arsalan Khan and Mr. Kamran Minai for contributing during various phases of data collection and data management in the study. We are highly indebted to study participants for providing useful information and their valuable time.

\section{Funding}

This study was funded through the Seed Money Grant (PF20/0512), Aga Khan University, Karachi. Additional support was provided by the Chiesi Pakistan (Pvt.) Limited. The BOLD Centre (PB) was funded by a grant from the Wellcome Trust (085790/Z/08/Z). Funding sources did not have any role in the design, conduct or reporting of this study.

Availability of data and materials

The data of this study is available from the corresponding author on reasonable request. 


\section{Authors' contributions}

AAN conceptualized the study, wrote the proposal and acquired funding; he also supervised the implementation of the study, as well as analysis and manuscript writing process. UR assisted in writing the proposal and acquiring grant, training of field staff, supervision of the data collection process, as well as writing the manuscript. SR supervised the data collection process, analyzed data and wrote the manuscript. MI supervised the training of technicians for conducting spirometry and helped with interpretation of spirometry results; he also contributed in writing the manuscript. SN contributed in data collection and data management processes and assisted in writing the manuscript. MAK contributed in data collection and data management processes. ZF provided mentorship throughout the conceptualization and implementation phases of the study. PB provided mentorship throughout the implementation, data analysis and writing-up phases of the study, he also helped in critically reviewing and improving the final draft of the manuscript. All authors read and approved the final manuscript.

\section{Ethics approval and consent to participate}

Ethical approval for the study was taken from Ethical Review Committee at Aga Khan University (2311-CHS-ERC-12). Prior to the interview, written informed consent was obtained from each respondent. The purpose and nature of the study was explained and spirometry procedure was demonstrated. Participants identified with any abnormality on spirometry were provided the report and were counselled and referred for further workup and management.

\section{Consent for publication}

Not applicable

\section{Competing interests}

The authors declare that they have no competing interests.

\section{Publisher's Note}

Springer Nature remains neutral with regard to jurisdictional claims in published maps and institutional affiliations.

\section{Author details}

'Department of Community Health Sciences, Aga Khan University, Stadium Road, P.O. Box-3500, Karachi 74800, Pakistan. ${ }^{2}$ Saudi Board Family Medicine, Ministry of Health, Buraidah, Kingdom of Saudi Arabia. ${ }^{3}$ Department of Medicine, Section of Pulmonology, Aga Khan University, Karachi, Pakistan. ${ }^{4}$ Respiratory Epidemiology and Public Health, National Heart \& Lung Institute, Imperial College London, London, UK. ${ }^{5}$ Population Health and Occupational Disease, National Heart and Lung Institute (NHLI), Imperial College London, London, UK. ${ }^{6}$ Department of Community Health Sciences, Ziauddin University, Karachi, Pakistan.

Received: 8 June 2018 Accepted: 26 November 2018 Published online: 04 December 2018

\section{References}

1. Masoli M, Fabian D, Holt S, Beasley R. The global burden of asthma: executive summary of the GINA dissemination committee report. Allergy. 2004;59(5):469-78.

2. Burney $P$, Jarvis $D$, Perez-Padilla R. The global burden of chronic respiratory disease in adults. Int J Tuberc Lung Dis. 2015;19(1):10-20.

3. Subbarao P, Mandhane PJ, Sears MR. Asthma: epidemiology, etiology and risk factors. Can Med Assoc J. 2009:181(9):E181-E90.

4. Canova C, Heinrich J, Anto JM, Leynaert B, Smith M, Kuenzli N, Zock J-P, Janson C, Cerveri I, De Marco R. The influence of sensitisation to pollens and moulds on seasonal variations in asthma attacks. Eur Respir J. 2013;42(4):935-45.

5. Song W-J, Kang M-G, Chang Y-S, Cho S-H. Epidemiology of adult asthma in Asia: toward a better understanding. Asia Pac Allergy. 2014;4(2):75-85.

6. Sá-Sousa A, Jacinto T, Azevedo LF, Morais-Almeida M, Robalo-Cordeiro C, Bugalho-Almeida A, Bousquet J, Fonseca JA. Operational definitions of asthma in recent epidemiological studies are inconsistent. Clin Transl Allergy. 2014;4(1):24.

7. Jindal SK, Aggarwal A, Gupta D, Agarwal R, Kumar R, Kaur T, Chaudhry K, Shah B. Indian study on epidemiology of asthma, respiratory symptoms and chronic bronchitis in adults (INSEARCH). Int J Tuberc Lung Dis. 2012;16(9):1270-7.

8. Fazlollahi MR, Najmi M, Fallahnezhad M, Sabetkish N, Kazemnejad A, Bidad K, Shokouhi Shoormasti R, Mahloujirad M, Pourpak Z, Moin M. The prevalence of asthma in Iranian adults: the first National Survey and the Most recent updates. Clin Respir J. 2018;12(5):1872-81.

9. Toren K, Brisman J, Järvholm B. Asthma and asthma-like symptoms in adults assessed by questionnaires: a literature review. Chest. 1993;104(2):600-8.

10. Global Initiative for Asthma. Global Strategy for Asthma Management and Prevention, 2018. Available from: www.ginasthma.org. Accessed 05 Dec 2016.

11. Agrawal S, Pearce N, Ebrahim S. Prevalence and risk factors for self-reported asthma in an adult Indian population: a cross-sectional survey. Int J Tuberc Lung Dis. 2013;17(2):275-82.

12. Karachi Metropolitan Corporation. Official webportal of Karachi Metropolitan Corporation Karachi, Sindh Available from: http://www.kmc.gos.pk/Contents. aspx?id=14. Accessed 15 Apr 2017.

13. Hasan A, Mohib M. Understanding slums: Case studies for the global report on human settlements: The case of Karachi, Pakistan. In: UN-Habitat. Global Report on Human Settlements 2003. The Challenge of Slums. London: Earthscan; 2003

14. Dejsomritrutai W, Nana A, Chierakul N, Tscheikuna J, Sompradeekul S, Ruttanaumpawan P, Charoenratanakul S. Prevalence of bronchial hyperresponsiveness and asthma in the adult population in Thailand. Chest. 2006;129(3):602-9.

15. Kuehni C, Strippoli MP, Low N, Silverman M. Asthma in young south Asian women living in the United Kingdom: the importance of early life. Clin Exp Allergy. 2007;37(1):47-53.

16. ECRHS. European Community Respiratory Health Survey, questionnaires, protocols and instructions. 2007. Available from http://www.ecrhs.org/ quests.htm. Accessed 09 Nov 2018.

17. Abbasi IN, Ahsan A, Nafees AA. Correlation of respiratory symptoms and spirometric lung patterns in a rural community setting, Sindh, Pakistan: a cross sectional survey. BMC Pulm Med. 2012;12(1):81.

18. Ferris B. Recommended respiratory disease questionnaire for use with adults and children in epidemiological research. Epidemiology Standardisation Project. Am Rev Respir Dis. 1978;118:1-35.

19. Pellegrino R, Viegi G, Brusasco V, Crapo R, Burgos F, Rea C, Coates A, Van der Grinten C, Gustafsson P, Hankinson J. Interpretative strategies for lung function tests. Eur Respir J. 2005;26(5):948-68.

20. Miller MR, Hankinson J, Brusasco V, Burgos F, Casaburi R, Coates A, Crapo R. Enright Pv, Van Der Grinten C, Gustafsson P. Standardisation of spirometry. Eur Respir J. 2005;26(2):319-38.

21. Stenton C. The MRC breathlessness scale. Occup Med. 2008;58(3):226-7.

22. City District Government Karachi. Karachi strategic development plan 2020. 2007.

23. Misra A, Chowbey P, Makkar B, Vikram N, Wasir J, Chadha D, Joshi SR, Sadikot S, Gupta R, Gulati S. Consensus statement for diagnosis of obesity, abdominal obesity and the metabolic syndrome for Asian Indians and recommendations for physical activity, medical and surgical management. J Assoc Physicians India. 2009;57:163-70.

24. International Labour Organization (ILO). The International Standard Classification of Occupations 2008 (ISCO-08): Structure, group definitions and correspondence tables Geneva, Switzerland: International Labour Office; 2012 Available from: http://www.ilo.org/public/english/bureau/stat/isco/ isco08/index.htm. Accessed 28 Nov 2018.

25. Obel KB, Ntumba KJM, Kalambayi KP, Zalagile AP, Munogolo KZ. Prevalence and determinants of asthma in adults in Kinshasa. PLoS One. 2017;12(5): e0176875.

26. Amiri A, Asadi S, Almasi $V$, Ghobadi A. The prevalence of asthma in an adult population in Khorramabad. Iran West Indian Med J. 2014;63(5):443.

27. Adams R, Wilson D, Appleton S, Taylor A, Dal Grande E, Chittleborough C, Ruffin R. Underdiagnosed asthma in South Australia. Thorax. 2003;58(10): 846-50.

28. De Marco R, Cerveri I, Bugiani M, Ferrari M, Verlato G. An undetected burden of asthma in Italy: the relationship between clinical and epidemiological diagnosis of asthma. Eur Respir J 1998;11(3):599-605.

29. Boskabady $\mathrm{MH}$, Kolahdoz $\mathrm{GH}$. Prevalence of asthma symptoms among the adult population in the city of Mashhad (north-east of Iran). Respirology. 2002;7(3):267-72.

30. Bousquet PJ, Hooper R, Kogevinas M, Jarvis D, Burney P. Number of allergens to be tested to assess allergenic sensitization in epidemiologic 
studies: results of the European Community respiratory health survey I. Clin Exp Allergy. 2007;37(5):780-7.

31. De Marco R, Marcon A, Rossi A, Antó JM, Cerveri I, Gislason T, Heinrich J, Janson C, Jarvis D, Kuenzli N. Asthma, COPD and overlap syndrome: a longitudinal study in young European adults. Eur Respir J 2015:ERJ00086-2015.

32. Benson MK. Bronchial hyperreactivity. Respir Med. 1975;69:227-39.

33. Backman H, Hedman L, Jansson S-A, Lindberg A, Lundbäck B, Rönmark E. Prevalence trends in respiratory symptoms and asthma in relation to smoking-two cross-sectional studies ten years apart among adults in northern Sweden. World Allergy Organ J. 2014;7(1):1.

34. Cerveri I, Cazzoletti L, Corsico AG, Marcon A, Niniano R, Grosso A, Ronzoni V, Accordini S, Janson C, Pin I. The impact of cigarette smoking on asthma: a population-based international cohort study. Int Arch Allergy Immunol. 2012;158(2):175-83.

35. James AL, Palmer L, Kicic E, Maxwell PS, Lagan SE, Ryan GF, Musk AW. Decline in lung function in the Busselton health study: the effects of asthma and cigarette smoking. Am J Respir Crit Care Med. 2005;171(2):109-14.

36. Accordini $S$, Janson C, Svanes C, Jarvis D. The role of smoking in allergy and asthma: lessons from the ECRHS. Curr Allergy Asthma Rep. 2012;12(3):185-91.

37. Patel S, Henderson J, Jeffreys M, Smith GD, Galobardes B. Associations between socioeconomic position and asthma: findings from a historical cohort. Eur J Epidemiol. 2012;27(8):623-31.

38. Basagaña X, Sunyer J, Kogevinas M, Zock J-P, Duran-Tauleria E, Jarvis D, Burney $\mathrm{P}$, Anto JM. Socioeconomic status and asthma prevalence in young adults: the European Community respiratory health survey. Am J Epidemiol. 2004;160(2):178-88.

39. Arathimos R, Granell R, Henderson J, Relton CL, Tilling K. Sex discordance in asthma and wheeze prevalence in two longitudinal cohorts. PLoS One. 2017;12(4):e0176293.

40. Magitta NF, Walker RW, Apte KK, Shimwela MD, Mwaiselage JD, Sanga AA, Namdeo AK, Madas SJ, Salvi SS. Prevalence, risk factors and clinical correlates of COPD in a rural setting in Tanzania. Eur Respir J. 2018;51(2):1700182.

41. Danielsson P, Ólafsdóttir IS, Benediktsdóttir B, Gíslason T, Janson C. The prevalence of chronic obstructive pulmonary disease in Uppsala, Swedenthe burden of obstructive lung disease (BOLD) study: cross-sectional population-based study. Clin Respir J. 2012;6(2):120-7.

Ready to submit your research? Choose BMC and benefit from:

- fast, convenient online submission

- thorough peer review by experienced researchers in your field

- rapid publication on acceptance

- support for research data, including large and complex data types

- gold Open Access which fosters wider collaboration and increased citations

- maximum visibility for your research: over $100 \mathrm{M}$ website views per year

At $\mathrm{BMC}$, research is always in progress.

Learn more biomedcentral.com/submissions 